\title{
Preface for the Special Issue Dedicated to J. Fröhlich, T. Spencer and H. Spohn
}

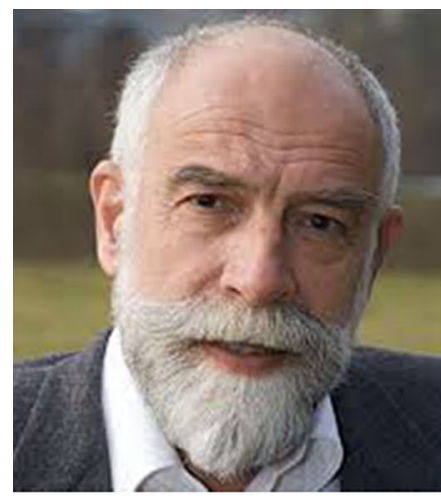

Jürg Fröhlich

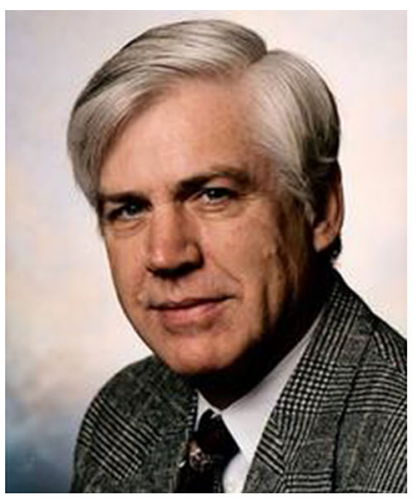

Thomas C. Spencer

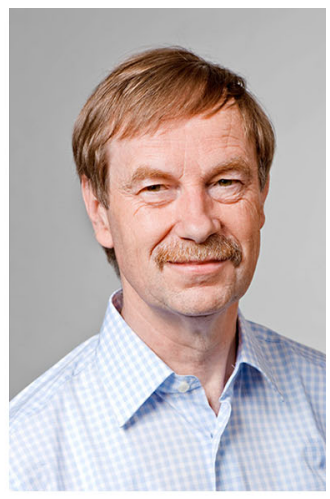

Herbert Spohn

It is truly a pleasure to dedicate this issue of the Journal of Statistical Physics to three colleagues and friends who have contributed so much to the field. I'm sure that the whole statistical mechanics and mathematical physics communities join me and the contributors to this issue in wishing them many healthy and creative years full of joy.

Joel Lebowitz, Editor-in-chief 